\title{
Experimental Research on the Influence of the Residence Time on the Safety of Secondary Water Supply ${ }^{1}$
}

\author{
Xu Guiqin ${ }^{1, a}$, Shu Mushui ${ }^{2, b}$, An Yan ${ }^{3, c}$ \\ ${ }^{1}$ Department of Safety Engineering, China Institute of Industrial Relations, No.45 Zengguang \\ Road, Haidian District, Beijing 100048, China ; 2 Industrial Hygiene Laboratory, Beijing Municipal \\ Institute of Labour Protection, No.55 Taoranting Road, Xicheng District, Beijing ; 3 China \\ Architecture Design Group, No. 19 Chegongzhuang Street, Xicheng District, Haidian District, \\ Beijing, China \\ a xuguiqin2003@126.com, b shumushui222@sina.com ,c 1215980043@qq.com
}

\begin{abstract}
Keywords: Secondary Water Supply, Residence Time, Water Quality, Organics
Abstract. The safety of drinking water has a direct impact on human health. In this paper, indicators of organic matterin the water stayed overnight and the water flow in two of the most common kinds of pipe materials-galvanized steel and PPR are analyzed experimentally, which indicates that the concentrations of TOC and CODMn in the overnight water are higher than those in water flow, and that galvanized steel pipes have a greater effect on the quality of water than PPR pipes. The results of GC-MS show that comparing to water flow, the concentrations of 6 sorts of organics increase and there are 12 sorts of new organics, and that the total peak area increases by $1704 \%$ in the overnight water in galvanized steel pipes, while the concentrations of 6 sorts of organics increase with 7 sorts of new organics, and the total peak area increases by $1660 \%$ in the overnight water in PPR pipes. The new added organics are mainly alkanes, olefins, alcohols and acids. For the residence time influences the quality of water evidently, it's advised to drink after taking appropriate measures.
\end{abstract}

\section{Introduction}

There are many factors that influence the quality of secondary water, among which the residence time and the pipe materials have serious impacts on it. As for the influence of the pipe materials of secondary water supply on the quality of water, the research mainly focuses on the new pipe materials with a residence time of $1,2,7 \mathrm{~d} \mathrm{etc} \mathrm{c}^{[1,2]}$. Other researches have also indicated that the performance of the pipe materials are getting stable after the use of over $200 \mathrm{~d}^{[4]}$. For the actual users, the most common situation they face is the water stayed overnight and they concern about whether it's safe. Owing to the fact that the toxicological indicators prescribed by the sanitary standard for drinking water are mainly the indicators of organic matter, the study takes a students' dormitory as an example, takes water samples at different periods of time during the early morning, and detects it with the primary object of the organics, which illustrates the effects of the residence time and the pipe materials on the safety of water.

\section{Materials and Methods}

\section{Experiment Object}

The water house on $8^{\text {th }}$ floor in students' dormitory on the main campus is taken as the water point and the experiment object. The 7-year-old building utilizes no negative pressure water supply equipment, and the water risers in the building are PPR pipes with galvanized steel at the end of branch pipes. According to the observations on the schedules of the students, nobody uses water at $5 \mathrm{am}$, and the water use summit comes at 6:30-7:50. Thus, the water sampling design is: sample at 5 am when it is stayed overnight in the galvanized steel at the end of the branch pipes, and mark it as water sample 1; sample after turning on the water for 5 minutes to ensure the overnight water in the galvanized steel at 
the end of the pipe has been emptied when it's the water sample stayed overnight in the PPR riser pipe, and mark it as water sample 2; sample after turning on the water for 5 minutes at 7:50 when it has the shortest residence time in the pipes and is least affected by the secondary water supply pipes, and mark it as water sample 3 .

\section{Item Measurement and Analysis Methods}

Conventional sensory index, residual chlorine and organic parameters CODMn, TOC are measured directly after sampling. Indicators of organic matter and metal indicators need to be measured after the sample preparation. Indicators of organic matter are first processed in accordance with the experimental methods in sample preparation in appendix B, GB-T5750.8-2006. After 1L of the sample is subjected to Solid Phase Extraction, organic solvent elution, nitrogen blowing and is fixed volume to $0.5 \mathrm{ml}$, it goes through qualitative detection by GC-MS ( GCMS-QP2010 Plus-shimadzu ) and semi-quantitative by toluene standard sample. TOC is measured by Shimadzu TOC-L shimadzu, $\mathrm{COD}_{\mathrm{Mn}}$, Chroma and residual chlorine by the United State HACH DR3900, turbidity by the United State HACH 2100Q.

Experimental Basis is as follows.

(1) Standards for drinking water quality (GB 5749-2006)(2)Standard examination methods for drinking water - Organic parameters GB-T 5750.8-2006) (3)Standard examination methods for drinking water - Aggregate organic parameters( GB-T 5750.7-2006)

\section{Results and Discussion}

\section{General Test Results}

By sampling at different periods of time, water in galvanized steel, PPR pipes and municipal pipe network is gathered; and by detecting the residual chlorine, $\mathrm{pH}$ value, Chroma, turbidity, COD and TOC of the water, the results are shown in Figure 1.

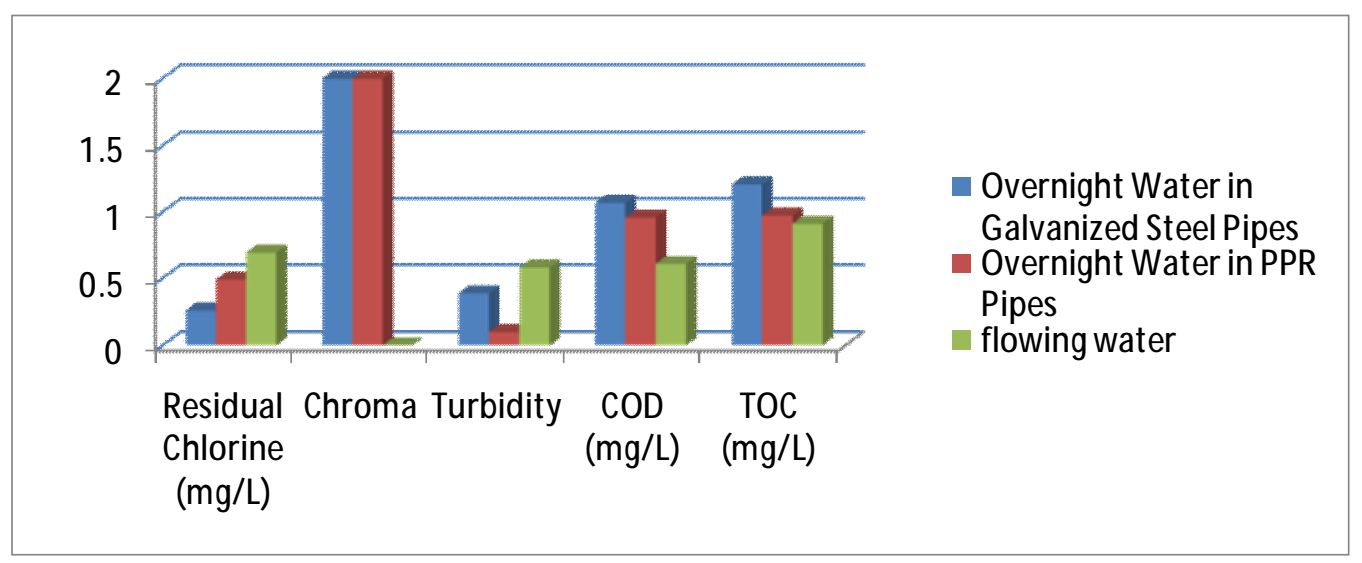

\section{Figure 1 Conventional Detection Results of Water Samples in Galvanized Steel, PPR Pipes and Municipal Pipe Network}

It's shown in table 1 that the 5 detection indicators of the 3 water samples all meet the drinking water hygiene requirements, and that the quality of water flow is better than that of the overnight water in PPR pipes, and the latter one is better than the overnight water in galvanized steel pipes. From the water flow, the overnight water in PPR pipes to the overnight water in galvanized steel pipes, the concentrations of residual chlorine decline sequentially, and those of TOC, CODMn increase successively. PPR pipes' is relatively smooth, and it's not easy for biofilm to attach. Comparatively, galvanized steel pipes' wall is uneven with a large number of micro-organisms attached to it due to the corrosion and other factors, which results in the loss of residual chlorine ${ }^{[3]}$. As for the turbidity, the partially detached biofilm leads to the increase of it, and the scouring action of the water flow makes it greater than that of the overnight water. The COD and TOC values of the two groups of overnight water samples have significant correlations, which is consistent with others' research. 


\section{Analysis of the Organics GC-MS's detection results}

The detection results of GC-MS shows that there are 7 kinds of organics detected in the water flow, that are toluene, ethylbenzene, ortho-xylene, 1,2-dichlorobenzene, alkane, 1-dodecene and phthalate, 5 kinds of which including benzenes and phthalate have the limited requirements in the drinking water standards. But their concentrations are far lower than the corresponding limit value inStandards for drinking water quality GB5749-2006. The first 4 sorts of benzene are mainly used as solvent, while the phthalate is widely used as plasticizers and is often detected in drinking water.

The analysis of results by GC-MS Spectra of overnight water in both galvanized steel and PPR pipes are shown in Table 1 and Table 2.

Table 1. Changes of Organics in Overnight Water in Galvanized Steel Pipes Compared with Water Flow

\begin{tabular}{|c|c|c|c|c|}
\hline & Name & $\begin{array}{l}\text { Total } \\
\text { Area }\end{array}$ & $\begin{array}{c}\text { Peak Concentration } \\
\mathrm{mg} / \mathrm{L})\end{array}$ & $\begin{array}{c}\text { ( Increment } \\
(\mathrm{mg} / \mathrm{L})\end{array}$ \\
\hline 1 & 1,2-Dichlorobenzece & 707648 & 0.0291 & 0.0239 \\
\hline 1 & Undecane & 385321 & 0.0159 & 0.0098 \\
\hline 2 & Dodecane & 99930 & 0.0041 & 0.0025 \\
\hline 3 & Hexadecane & 40569 & 0.0017 & 0.0017 \\
\hline 4 & Pentadecane & 91128 & 0.0037 & 0.0037 \\
\hline 5 & Tetradecane & 120366 & 0.0050 & 0.0050 \\
\hline 6 & 7- Methylene Tridecane & 254436 & 0.0105 & 0.0105 \\
\hline 7 & 2- Methyl-1-Dodecene & 353996 & 0.0146 & 0.0146 \\
\hline 8 & 3- Methyl-Pentadecane & 49161 & 0.0020 & 0.0020 \\
\hline 9 & 3- Methylene Tridecane & 1287530 & 0.0530 & 0.0359 \\
\hline 10 & n- Pentadecanol & 6605742 & 0.2718 & 0.2718 \\
\hline 11 & Ring Isohexadecane & 6359615 & 0.2616 & 0.2616 \\
\hline 12 & 1- Hexadecene & 3727117 & 0.1533 & 0.1533 \\
\hline 13 & Nonadecene Ene & 647219 & 0.0266 & 0.0266 \\
\hline 14 & Heneicosanoic & 1045310 & 0.0430 & 0.0400 \\
\hline 15 & Stearate & 632610 & 0.0260 & 0.0041 \\
\hline 16 & Phthalates & 128321 & 0.0053 & 0.0053 \\
\hline 17 & Octadecenoic Acid Amide & 121773 & 0.0050 & 0.0050 \\
\hline
\end{tabular}


Table 2. Changes of Organics in Overnight Water in PPR Pipes Compared with Water Flow

\begin{tabular}{|c|c|c|c|c|}
\hline & Name & Total Peak Area & $\begin{array}{l}\text { Concentration } \\
(\mathrm{mg} / \mathrm{L})\end{array}$ & $\begin{array}{l}\text { Increment } \\
(\mathrm{mg} / \mathrm{L})\end{array}$ \\
\hline 1 & 1,2-Dichlorobenzene & 897945 & 0.0343 & 0.0290 \\
\hline 2 & Undecane & 473916 & 0.0181 & 0.0120 \\
\hline 3 & Tetradecane & 117218 & 0.0045 & 0.0024 \\
\hline 4 & 3-Ethyl-1,1-Dimethyl - cyclopentane & 268938 & 0.0103 & 0.0103 \\
\hline 5 & 2-Methyl-1-Dodecene & 378123 & 0.0144 & 0.0144 \\
\hline 6 & 3-Methylene Tridecane & 1440162 & 0.0550 & 0.0379 \\
\hline 7 & n- Pentadecanol & 6619946 & 0.2528 & 0.2528 \\
\hline 8 & Ring Isohexadecane & 6667412 & 0.2546 & 0.2546 \\
\hline 9 & 1- Hexadecene & 3933284 & 0.1502 & 0.1502 \\
\hline 10 & Heneicosanoic & 575047 & 0.0220 & 0.0190 \\
\hline 11 & Stearate & 1444152 & 0.0551 & 0.0332 \\
\hline 12 & Eicosyl & 170636 & 0.0065 & 0.0065 \\
\hline 13 & Squalane & 162224 & 0.0062 & 0.0062 \\
\hline
\end{tabular}

Comparing with the water flow, the concentrations of 6 kinds of organics increase in the overnight water in galvanized steel pipes, and there are 12 kinds of new organics in it, with the total peak area increased by 1704\%. In the overnight water in PPR pipes, 6 kinds of organics concentrations increase and there are 7 kinds of new organics, with the total peak area increased by $1660 \%$. The new added organics are main alkane, olefin, alcohol and acid. As is shown, the impacts of galvanized steel on the increase in organics' amounts and their concentrations are both greater than those of PPR pipes'. The reason is that PPR pipes are a sort of plastic pipes, whose organic matter in the pipe materials deposits and makes the organics' amounts larger and their categories more than those in galvanized steel pipes. But with the extension of the use time, this kind of ability to deposit gradually weakens, and the pipe materials tend to be stable. Additionally, since PPR pipes are not easy to corrode, the pipe wall keeps relatively smooth though it still has some metal precipitates, and is attached by a small amount of biofilm. Whereas, as the use time goes by, the galvanized steel pipes' inner wall becomes uneven because of the corrosion, and the area of the cross-section gets smaller, and the corrosion deposits along with the biofilm attachment increase, which brings about its more and more serious influence on the quality of water ${ }^{[4]}$.

It's easy to form the dead zone at the end of the secondary water supply network. Besides, since the pipe diameter is comparatively thick, the influence of pipe materials on water quality is relatively more significant, so the residence time is an important factor affecting water quality.

\section{Conclusions}

(1) Benzene, phthalate and other 3 kinds of organics with limit value in the Sanitary standard for drinking water are detected in the water flow at the end of the pipe network in the students' dormitory, but they are far from exceeding the standard.

(2) The concentrations of TOC and $\mathrm{COD}_{\mathrm{Mn}}$ in the overnight water in galvanized steel pipes are obviously higher than those in water flow. The impact of galvanized steel pipes is greater than that of PPR pipes. 
(3) The test results have revealed that comparing with the water flow, there are respectively 12 and 7 kinds of new added organics in galvanized steel and PPR pipes. Besides, concentrations of 6 kinds of organics increase in both pipes, and the added organics are mainly Hydrocarbon enols.

(4) Changes in organics in the overnight water stayed in the secondary water supply network are significant, so it's not recommended to drink directly.

\section{References}

[1] Zhang Lei, Yu Haiye, Liu Jia. Research Progress of the impacts of Plasic water supply piping to water safety: Journal of Safety and Environment, , Vol.11 (2011), P:158-161

[2] Zhang Ling, Liu Shuming, Hu Hongying Research of organic compounds migration from polymeric pipes:China Environmental Science, Vol.34 (2014), P:1478-1484

[3] Markku J. Lehtola,Ilkka T. Miettinen.Microbiology, chemistry and biofilm development in a pilot drinking water distribution system with copper and plastic pipes: Water research, Vol.38 (2004),P: 3769-3779.

[4] Lin J, Ellaway M, Adrien R. Study of corrosion material accumulated on the inner wall of steel water pipe : Corrosion Science, Vol.43.(2001),P:2065-2081. 